\title{
O Desenho Sonoro em "Os Cegos", de Denis Marleau
}

\section{*Maíra Castilhos Coelho}

\section{Resumo}

O artigo pretende analisar a construção sonora da peça "Os cegos", de Maurice Maeterlinck, encenada por Denis Marleau. Nesta encenação a sonorização dos atores e as manipulações operadas sobre as vozes não visam produzir efeitos especiais, mas sim harmonizar o desenho sonoro do palco. Há uma articulação entre o sentido, a voz, as formas e o ritmo, e esses elementos surgem para reforçar o texto literário. Como o ator não está presente fisicamente na cena, somente a projeção de sua imagem, talvez a presença do ator surja através de sua voz. E como o som é a propagação de uma onda mecânica, que se espalha pelo espaço, talvez a voz do ator consiga ultrapassar o veículo mediador e ter presença, uma presença sonora.

Palauras-chave: teatro - sonoridade presença.

\begin{abstract}
This paper intend to analyse the poetic voice of the presentation the play 'The Blinds', by Maurice Maeterlinck and staged by Denis Marleau. The sound of the actors and the manipulations operated on the voices are not intended to produce special effects, but rather seek to harmonize the sound design of the stage. There is a link between the meaning, the voice, the shapes and rhythm, and these elements appear to strengthen the literary text. As the actor is not physically present at the scene, only on the projection of its image, perhaps the presence of the actor emerges through her voice. And how sound is the propagation of a mechanical wave, which spreads through space, perhaps the actor's voice will pass the vehicle mediator and have a presence, a sound presence.
\end{abstract}

keywords: theatre-loudness - presence 
A peça "Os Cegos" (1890) marca os primeiros tempos de Maurice Maeterlinck como dramaturgo. Sem ação, a peça apresenta doze cegos perdidos numa floresta escura, à espera de seu guia. Através de uma linguagem simples e moderna, questiona a nossa própria cegueira e incapacidade, como humanos, de compreender e definir o que é a morte. É a partir deste texto que Denis Marleau trabalha com a presença de corpos ausentes. Dando ênfase à palavra e utilizando recursos tecnológicos, Marleau cria uma “teatralidade do espectro", perfeita para o texto de Maeterlinck.

No palco, são exibidas doze projeções perfeitas, em tamanho real. Dois atores são transformados em seis, resultando em doze personagens em cena. Seis homens do lado direito e seis mulheres do lado esquerdo. Aos poucos, começam a acordar e a dialogar. Gradualmente, a sala começa a ser preenchida por uma atmosfera de agonia, silêncio e escuridão. Nesse ambiente do ausente, da morte, há uma busca desesperada por sons. Como se os personagens estivessem a procura de uma polifonia para fugir do silêncio, da mudez do guia que não responde, da morte... "O homem teme a ausência de som como teme a ausência de vida [...] O último silêncio é a morte" (SHAFER, 1991, p. 69-72)

Marleau constrói um espaço cênico onde as vozes podem se elevar e se fazer entender. Em "Os Cegos", há uma articulação entre o sentido, a voz, as formas e o ritmo, e esses elementos surgem para reforçar o texto literário. Uma vez que os cegos não usam seus olhos, durante o espetáculo o público compartilha essa experiência sem conseguir distinguir a origem e a materialidade dos ruídos e dos sons que invadem o espaço cênico. Nesse sentido, a fronteira entre o que eles ouvem e o que eles acreditam ouvir rompe o espaço e o tempo.

\section{A construção sonora de Nancy Tobin}

A pesquisa de Marleau sobre o som da voz em cena começou com "Les trois jours derniers de Fernando Pessoa”, onde o ator Paul Savoie representava com as efígies. Para o diretor, era necessário encontrar uma maneira de harmonizar a voz gravada e a voz do ator em cena. Nesta busca, após conhecer o trabalho Nancy Tobin através do website intitulado RestArea ${ }^{1}$, estabeleceu uma parceria com a designer sonora, nas criações do UBU.

Nancy Tobin é uma designer de som de Montreal, especializada em sistemas sutis de amplificação. Esta amplificação é feita através do uso de alto-falantes, com os quais ela consegue criar atmosferas sonoras intimistas. Trata-se, portanto, de um trabalho de eletroacústica inspirado em microsound ${ }^{2}$ e em formas de música glitch ${ }^{3}$, que possibilitam o surgimento do chamado efeito acousmatic ${ }^{4}$ no espaço cênico. Este efeito se dá através das qualidades tonais das vozes amplificadas e da "voz" de sons pré-gravados amplificados através de vários alto-falantes.

O estilo de Tobin ficou conhecido pela amplificação vocal que soa natural, bem como a manipulação de som com vários tipos de alto-falantes. Esta tecnologia desenvolvida pela designer possibilitou ao teatro usufruir da intimidade do cinema, pois o ator pode sussurrar ou fazer pequenos sons sem a necessidade de projetar a voz para o palco.

A experiência com os alto-falantes de Tobin levou Marleau a orientar o trabalho dos atores em direção à maior modulação possível da voz. Além disso, essas amplificações possibilitaram experiências poéticas, abstratas e minimalistas na criação de "Os Cegos".

Assim, o trabalho de Tobin com Denis Marleau é bastante rico, pois o próprio diretor enfatiza a sonoridade nas suas criações. Em função disso, o trabalho de Tobin acontece desde o início de uma produção, para que os elementos sonoros sejam criados em paralelo ao desenvolvimento dos personagens.

\footnotetext{
$\bar{l}$ O site é composto por um suave aviớo azul habitado por retângulos coloridos lentamente ò deriva pela tela; lembrando intencionalmente um padrã̃o de teste de imagem para televisẫo ou uma pintura Piet Mondrian. A trilha sonora que acompanha é o microsound ilk - um ritmo de clique em camadas, juntamente com outros tons mínimos. RestArea ganhou o First Prix du Public em Les HTMlles 2001 e foi exibido no New Museum of Contemporary Art, em Nova York, mas Nancy Tobin é mais conhecida como designer de som para o palco. Seu trabalho fez parte do Festival de Théâtre dês Amériques, Festival Internacional de la Nouvelle Danse, World Stage (http://www.mmebutterfly.com/restarea/)

2 Microsound: inclui todos os sons em uma escala de tempo mais curta do que a das notas musicais.

3 Glitch é um termo usado para descrever um gênero da música eletrônica que surgiu em meados da década de 1990 . A estética da "falha" é caracterizada por um uso proposital de falhas e interferências baseada em recursos sonoros que normalmente seriam vistos como distúrbios indesejáveis em gravações de audio.

$4 \quad$ Som que se ouve sem saber de onde se origina.
} 
Para amplificar o som vocal de forma natural e manipular o som com vários tipos de alto-falantes, é necessário atrasar (delay) a voz amplificada nos alto-falantes para encaixar com o tempo que o som acústico levaria para viajar do palco até os ouvidos do espectador. Este processo de calibragem dos delays é descrito por Tobin (apud site andrasound, internet) ${ }^{5}$ :

Os técnicos povoavam as poltronas mais distantes do palco' enquanto' no palco' um único alto falante emitia um pulso regular. Os delays eram definidos por consenso entre o grupo. Nancy ainda convida os amigos para visitar quando ela ajusta os delays em Montréal. ['.] No entanto' na hora que Tobin termina de instalar o sistema de som no local' os sons mais íntimos da voz e da respiração de um ator podem ser igualmente projetados para o público sem qualquer diferença entre a voz acús tica e a amplificada. Os contornos irregulares da sala refletem e difundem alternadamente o som, dependendo de onde se senta na plateia' causando pontos quentes e pontos mortos' A verificação dos ângulos envolve subir e descer lentamente cada fila da plateia' debruçando`se para estar na mesma altura que estaria a cabeça de uma pessoa sentada' enquanto a mesma música toca repetidamente pelo sistema de som. Os alto falantes são minuciosamente angulados' ajustados e reajustados. [] Tobin metodicamente cita cada medida de delay em segundos e nós ouvimos os sons acústicos amplificados aproximarem'se Ao final' a diferença entre um delay audivel e um inaudivel é uma questão de milissegundos. O consenso é surpreendentemente fácil neste grupo Todos conseguem ouvir o momento em que o alto'falante é sincronizado com o som acústico. Repete-se o mesmo processo em todas as filas de assentos' e segue o mesmo procedimento para os alto'falantes suspensos.

Para criar ambientes intimistas sob a direção de Denis Marleau, na peça "Les trois jours derniers" de Fernando Pessoa" (1997), Tobin adaptou este método de amplificação vocal imperceptível. O diretor buscava estabelecer um equilíbrio entre as duas vozes dos personagens no mesmo espaço. Assim, era necessário deixar a voz gravada mais natural e a voz do ator ao vivo mais "artificial". A fim de criar uma homogeneidade sonora, Paul Savoie colocou um microfone sem fio que amplificava ligeiramente sua voz e lhe permitia falar sem precisar projetá-la. O que, segundo Jasmim (2011) "permitiu ao mesmo tempo um acesso a intimidade da voz em todas suas inflexões sutis até o murmúrio" (p. 53). Além disso, para criar a ilusão de que as vozes dos atores não estavam amplificadas, a designer usou microfones invisíveis e alto-falantes, que foram sincronizados com a voz acústica no palco.

Assim, o trabalho de Tobin foi manter natural a voz mediada dos personagens através de técnicas de amplificação e escolha de alto-falantes. Para que as imagens parecessem tão reais quanto o ator, o ator que estava ao vivo também foi amplificado por um pequeno microfone invisível através de um alto-falante com a qualidade tonal correta, permitindo-o partilhar o mesmo espaço acústico das vozes gravadas. Para que ambas as vozes interajam no mesmo espaço, a voz do ator em tempo real é amplificada da mesma forma que a voz do ator virtual. As fontes de som são precisamente ajustadas de modo que pareçam ser provenientes do corpo dos personagens. Os níveis são verossímeis, imitando a intensidade das vozes acústicas no palco. Com isso, Marleau conseguiu a voz acústica que desejava:

Eu não quero fazer vozes de robô' porque não são robôs que eu coloco em cena. O que me interessa é a voz natural' acústica. Mais exatamente' é encontrar a maneira na qual a relação entre o intérprete que está em cena e o personagem que está registrado' filmado antecipadamente' possa se estabelecer sem um hiato. 'MARLEAU apud PROUST, 2010, p.60).

Marleau começou a utilizar estes microfones sem fios e dos quais a amplificação é apenas perceptível a fim de não uniformizar as vozes. Estes micros tornam compreensíveis os eufemismos a as hesitações mais sutis da voz permitindo que elas cheguem aos ouvidos dos espectadores.

Em “Os Cegos" cada personagem/máscara teve a sua fala emitida a partir de seu próprio alto-falante. Os recursos sonoros da peça foram fundamentais, pois toda a encenação é focada na sonoridade. Além disso, no texto, Maeterlinck descreve os sons que os cegos ouvem: respiração, vento, mar, pássaros, folhas e passos sobre as folhas. Assim, a designer buscou integrar esses sons (Foley) ${ }^{6}$ sem depender apenas dos efeitos sonoros

\footnotetext{
5 http://www.andrasound.org

6 Efeitos sonoros especiais criados artificialmente e inseridos em produções, especialmente de TV, cinema ou desenho animado, para realçar ou enfatizar.
} 
especiais criados artificialmente.

Percebi que todos os sons que Maeterlinck quis incluir na sua peça poderiam de alguma forma vir de um único instrumento. Todos esses sons são bastante semelhantes nos extremos de espectro da audição humana (TOBIN apud site andrasound' internet').

Deste modo, enfatizou a textura de cada som em suas frequências extremamente baixas ou muito altas, para criar uma atmosfera sonora que evocava um ambiente abstrato. Por exemplo "o som das ondas contra uma praia de cascalho torna-se um farfalhar frágil quando as frequências altas estão em primeiro plano ou pode soar como a respiração da própria terra quando as frequências mais baixas são ouvidas intensamente" (apud site andrasound, internet). Isso faz com que embora consigamos reconhecer os sons, exista uma atmosfera fantasmagórica e que a plateia seja transportada para a floresta através da audição.

A dimensão sonora era imensa Eu não só tive que criar o ambiente sonoro da floresta' mas também havia muitas gravações vocais e ampliações a serem feitas: A peça toda foi pré-gravada e depois apresentada através de projetores e alto-falantes. Cada personagem tinha o seu próprio projetor e alto-falante. $O$ efeito era a ilusão de personagens fantasmagóricos quase reais. Lembro'me de experimentar pelo menos ${ }^{16}$ modelos diferentes de alto-falantes' procurando desesperadamente $o$ que ajudaria as vozes a soarem mais naturais. []. Meu objetivo era criar um ambiente que parecesse extremamente crível' sem representar a realidade de uma forma naturalista· Quanto às vozes' para alcançar a credibilidade' localizações audiovisuais convergentes e reprodução de frequência transpar ente eram as premissas básicas 'TOBIN apud site andrasound' internet).

\section{Um teatro das vocalidades}

A sonorização do espetáculo e as manipulações operadas sobre as vozes dos atores não visam produzir efeitos especiais, mas sim, buscam harmonizar o desenho sonoro do palco. Dessa forma, o ambiente sonoro, fortemente inscrito no texto, confere à cena a sensação de estarmos sonhando acordados.

As vozes se transformam e sustentam as frases, comunicam não somente pelos signos, mas também por seus timbres e por sua elevação ou por suas flutuações sonoras, cantantes, murmurantes, grotescas e violentas. Segundo Krysinski (2002), "O teatro de Denis Marleau é uma construção multiforme e polidimensional. Sua dinâmica não é unidirecional. Eu me proponho considerar uma das dimensões deste teatro: a da manipulação da palavra” (p. 22).

Assim, a encenação chama a atenção pelo silêncio, pelas pausas e pela ausência do movimento e do humano. Transporta-nos a outro lugar, o do sonho, o do lúdico. Aguça a percepção auditiva com sons distantes, baixos, próximos e em coro. Provoca pela sensação de estarmos sendo observados, pelo invisível. Atores substituídos por imagens videográficas projetadas sobre máscaras de seu próprio rosto, que dialogam com o espectador.

Por outro lado' o locutor está deslocado' ele não está lá. O locutor estava na cabine quando ele fez o trabalho de gravação Mas existe um outro locutor que é o personagem que é locutor Mas o ator locutor não está lá Ele está em outro lugar. Ele está em outro espaço É isso E E isso só pode funcionar porque a ilusão é perfeita e porque o espectador acredita que é o personagem que fala 'FÉRAL' entre vista concedida em ${ }^{2010)}$

Ainda que o ator não esteja presente fisicamente, a sua voz chega ao ouvinte, e este está presente. Ao falar, a voz do personagem toca o espectador e se faz presente. E isso acontece, pois segundo Zumthor (2005), temos duas presenças, a da voz que fala e aquele para quem ela fala: "Assim, a voz, utilizando a linguagem para dizer alguma coisa, se diz a si própria, se coloca como uma presença” (p.63).

Um texto linear e irreversível e um tempo suspenso. Um verdadeiro teatro das vocalidades. Um retorno ao verbo. Temos a palavra como signo dominante nos limites de uma teatralidade. Uma teatralidade que seleciona e escolhe o verbal ao invés do visível ou do cinético. 
Como todo jogo' o texto vocalizado transforma'se em arte no seio de um lugar emocional manifestado em performance e de onde procede e para onde se dirige a totalidade das energias que constituem a obra viva. Este é' em parte' um lugar qualitativo' zona operadora da 'função fantasmática', segundo a expressão de Gilbert Durand' Mas é também um lugar concreto' topograficamente definivel' onde a palavra se desdobra e ao qual ela confia' em parte' a função de ordenar o discurso - ela' a palavra' que não é uma simples executora da língua' mas que carrega sua verdade própria A voz poética emerge' portanto' do fluxo mais ou menos indiferenciado dos ruidos e dos discursos. Ela faz o acontecimento (ZUMTHOR, ${ }^{2005,} p^{.145)}$

Nesse ambiente do ausente, do estático, da morte, há uma busca desesperada por sons. Como se os personagens estivessem a procura de uma polifonia para fugir do silêncio, da mudez do guia que não responde, da morte... "O homem teme a ausência de som como teme a ausência de vida [...] O último silêncio é a morte" (SHAFER, 1991, p. 71-72). E esta busca desesperada pela polifonia gera uma angustia, pois ela está baseada no silêncio.

Com os doze cegos petrificados nas sombras' que escutam tanto quanto não falam' o texto instaura um espaço mental dando a impressão de uma busca desesperada de sentido' como se os personagens estivessem a procura de uma polifonia ou de uma unidade perdida (ISMERT, 2002, $p^{.104) .}$

Deste modo, ao escutarmos o silêncio, a morte evidencia-se. E quando as vozes surgem no espaço, multiplicadas e harmônicas, elas nos aliviam. "A voz jaz no silêncio; às vezes ela sai dele, e é como um nascimento. Ela emerge de seu silêncio matricial” (ZUMTHOR, 2005, p. 63). Assim, o som representa a existência. Os atores falam para sentirem-se vivos. E, ao mesmo tempo em que os ruídos da floresta geram medo e angústia, eles tranquilizam, pois afirmam a vida.

O som corta o silêncio 'morte' com sua vida vibrante. Não importa o quão suave ou forte ele está dizendo: "Estou vivo". O som' introduzindo'se na escuridão e esquecimento do silêncio' ilumina`o (SHAFER, ${ }^{1991,} p^{.73)}$.

Além disso, como os atores estão projetados em cena, a imobilidade reforça ainda mais a audição como o sentido mais estimulado pela montagem. E talvez isso aconteça, pois, segundo Zumthor (1997), o interprete é composto por gesto e voz. "O interprete é o indivíduo de que se percebe, na performance, a voz e o gesto, pelo ouvido e pela vista” (p. 225). Desta forma, num espetáculo onde o personagem está imóvel, a interpretação acaba se concentrando na voz do ator. Assim, num ambiente escuro e silencioso, sem movimentação, passamos a ouvir todos os tipos de sons. A peça é um verdadeiro devaneio sonoro, que consagra o ator e a palavra, articulando a escuta e o silêncio.

Outra questão interessante é que neste texto de Maeterlinck, considerado um 'drama estático', todos os acontecimentos e movimentos são descritos pelos atores, o que nos leva a imaginar as ações, como numa peça radiofônica:

Segundo cego de nascença: - Por que você está cutucando esse meu cotovelo?

Primeiro cego de nascença:- Eu nem te encostei; não consigo alcançar você.

Segundo cego de nascença - Pois eu digo que alguém me cutucou o cotovelo!

Primeiro cego de nascença-Não foi nenhum de nós! (Maeterlinck, ${ }^{2009,} p^{.117)}$

Além disso, o intérprete dirige-se ao público, fazendo com que ocorra uma aproximação entre o real e o virtual, potencializando o efeito de presença.

Primeiro cego de nascença: - Estão ouvindo? - Estão ouvindo?

Segundo cego de nascença:- Não estamos sozinhos aqui!

Terceiro cego de nascença: ' Bem que eu desconfiava; alguém está nos escutando 'Maeterlinck, ${ }^{2009,} p$. 
E assim a voz estabelece um acontecimento no mundo sonoro. Pensar na materialidade do som pode parecer abstrato, isso porque ainda somos reféns de um conceito de corpo como parte visível da pessoa. Mas já sabemos que as emanações, o arfar de uma respiração, o pulso e o tônus de sua fala são também corpo. E este corpo também tem uma presença capaz de despertar reações nos ouvintes.
A linguagem se realiza no momento em que o "entre" se constitui: este campo' esta dimensão que se abre entre aquele que fala e aquele que escuta' entre aquele que propõe as imagens e aquele que as deixa ecoar em si produzindo significados. O espaço poético não pertence a nenhum dos jogadores. Instaura'se É Energia que conecta' É compartilhamento SETTI, 2007, $p .{ }^{31)}$.

Desta forma, a voz supõe um gesto fonético, produzindo um som habitado por significados. A linguagem é "invadida de presença" e se modifica tanto naquele que fala (ainda que em outro espaço e tempo) quanto naquele que escuta.

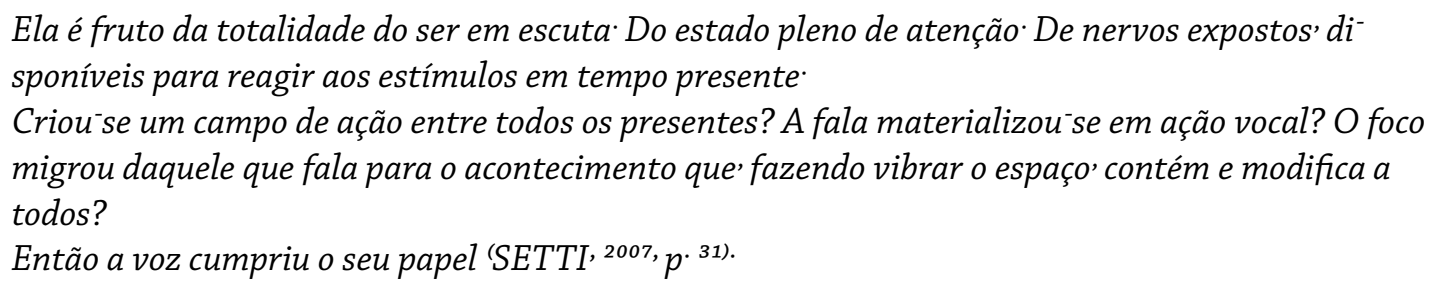

Na voz se inscreve também todo o não dito, o ritmo, a temperatura, a espessura e os traços marcantes. E é a voz que nos oferece a palavra e o silêncio. A voz vai do interior do intérprete ao interior do ouvinte, podendo modificá-lo. "Dizer também é tocar. Ao outro. Aos limites da linguagem" (PELICORI, 2007, p. 41). E segundo Barthes (1982), através da voz e do ouvido estabelecemos uma relação de contato e de troca:
A injunção de escutar é a interpelação total de um indivíduo a outro: coloca acima de tudo o contato quase físico desses dois indivíduos 'pela voz e pelo ouvido': cria a transferência: escute-me quer dizer: toque'me' saiba que existo; na terminologia de Jakobson' escute'me é um fático' um operador de comunicação individual ( $p$. 222).

Como o som é a propagação de uma onda, que se espalha pelo espaço, ele parte do ator e chega ao espectador materialmente. Portanto, uma voz, mesmo gravada, ultrapassa o veículo e alcança o ouvinte. Assim, a voz poética ocupa o espaço e toca o espectador, intensificando a sensação de presença do ator, através de uma presença sonora.
A performance da palavra supõe sua existência como onda sonora' pressente sua trajetória pelo espaço até tocar o corpo que escuta Assim prevista' esta palavra destrava a voz. Com o foco no dizer' o texto desprende-se da questão significar ou soar e alcança o patamar da comunicação através da experiência' do acontecimento 'SPRITZER, ${ }^{2009}{ }^{.33 \text {. }}$

Deste modo, embora o ator não esteja fisicamente presente, a voz nos provoca reações muito semelhantes das que temos quando estamos de fato diante de uma pessoa. O efeito de presença causa uma sensação no espectador de que os corpos oferecidos ao seu olhar ou à sua escuta estão realmente ali, no mesmo espaço e tempo em que ele se encontra.

É possível afirmar que o som e a voz são fundamentais para que o efeito de presença aconteça nessa encenação, uma vez que somos guiados pelo ouvido e não pelo olhar. É o ouvido que dá a identificação e a possibilidade do efeito de presença.

Eu digo que o ouvido é importante por que se houvesse apenas o ouvido eu diria que nós estávamos realmente na presença: Mas o ouvido junto com o olho permite ao espectador entender que na verdade se trata de um efeito de presença $O$ olhar na verdade vem contradizer o que o ouvido está 
escutando (FÉRAL' palestra realizada ${ }^{2010,}$ em Salvador).

A voz do intérprete, mesmo que esteja mediada, estimula uma reação no ouvinte. A oralidade mediatizada não deixa de ser uma voz. Fixando o som vocal, segundo Zumthor (1997), "a voz se liberta das limitações espaciais" (p. 29). Por outro lado, não temos a presença física do locutor, apenas o som fixo da sua voz. Porém, o ouvinte durante o espetáculo está inteiramente presente. Seu papel é tão importante quanto o do intérprete, pois sua recepção é um ato único e individual.

O ouvinte escuta' no silêncio de si mesmo' esta voz que vem de outra parte' ele a deixa ressoar em ondas' recolhe suas modificações' toda "argumentação" suspensa. Esta atenção se torna' no tempo de uma escuta' seu lugar' fora da língua' fora do corpo 'ZUMTHOR, 1997, $p$. 17).

É graças ao corpo verbal do ator que todas as coisas podem ser imaginadas e vistas pelo espectador. Em "Os Cegos” as ações são escutadas e não vistas. Porém a qualidade sonora da encenação permite que elas sejam tão ou mais extraordinárias do que se elas fossem mostradas.

Eu acho que a presença na voz concerne um duplo processo de manifestação: a significação das palavras - certamente - mas também' e eu acho que o aspecto mais importante' uma atmosfera que permite a significação das palavras de ter um impacto sobre alguém que recebe as palavras." E esta atmosfera é segundo minha perspectiva' a capacidade que tem um ator de trabalhar sobre a dimensão propriamente sonora das palavras. Esta consciência da sonoridade das palavras permite ao ator redobrar e amplificar o processo de colocar em presença de sua voz' por que ele é capaz de amplificar o "sentido" das palavras trabalhando sobre a dimensão sonora que o acompanha (PITOZZI' entrevista concedida em ${ }^{2010)}$.

Marleau aproveita o recurso sonoro, dando ênfase a uma voz poética e ao silêncio. Além disso, não há movimentação em cena e as imagens são estáticas, o que contribui com a atmosfera sonora presente no espetáculo.

\section{Referências:}

BARTHES, Roland. O óbvio e o obtuso. Rio de janeiro: Nova Fronteira, 1982.

ISMERT, Louise. Une fantasmagorie technologique, entretien avec Denis marleau, in: Modernité de Maeterlinck, Denis Marleau - Alternatives Théâtrales 73-74. Belgique, 2002.

Disponível em: WWW.alternativestheatrales.be/catalogue/revue/73-74

Acesso em 02 out. 2010.

JASMIN, Stéphanie e MARLEAU, Denis. Le processus singuliers d’UBU: masques tragiques et installations ludiques, In: Spirale, Canada, n.236, 2011.

TOBIN, Nancy. In and out of the studio. Disponível em http://www.andrasound.org/ Acesso: março, 2011. KRYSINSKI, Wladimir. Denis Marleau ou La sublimation de La forme, in: Modernité de Maeterlinck, Denis Marleau - Alternatives Théâtrales 73-74.

Belgique, 2002.

Disponível em: WWW.alternativestheatrales.be/catalogue/revue/73-74

Acesso em 02 out. 2010.

MAETERLINCK, Maurice. Los Ciegos. Madrid: Ediciones Cátedra, 2009.

PELICORI, Ingrid. Caligrafía de la voz. Buenos Aires: Leviatán, 2007.

PROUST, Sophie. Denis Marleau - introduction et entretiens, in: Actes Sud-Papiers. Paris: Leméac, 2010.

SCHAFER, R. Murray. O ouvido pensante. São Paulo: Editora da UNESP, 1991.

SETTI, Isabel. O corpo da palavra não é fixo deixa-se tocar pelo tempo e seus espaços. In: Sala Preta, n.7. São Paulo: ECA/USP, 2007, PP. 25 - 31.

SPRITZER, Mirna. Silêncio, escuta e a performance da palavra. Memória ABRACE, 2009. Disponível em: <http://portalabrace.org/portal/memorial> Acesso em 29 mar. 2010.

ZUMTHOR, Paul. Introdução à poesia oral. São Paulo: Ed. Hucitec, 1997.

. Escritura e Nomadismo. Cotia, SP: Ateliê Editorial, 2005. 